\title{
Reconciling Variable Findings of White Matter Integrity in Major Depressive Disorder
}

\author{
Ki Sueng Choi*,1,2,7, Paul E Holtzheimer 1,3,7, Alexandre R Franco ${ }^{4}$, Mary E Kelley ${ }^{5}$, Boadie W Dunlop', \\ Xiaoping P $\mathrm{Hu}^{2}$ and Helen S Mayberg ${ }^{1,6}$ \\ 'Department of Psychiatry, Emory University, Atlanta, GA, USA; ${ }^{2}$ The Wallace H Coulter, Department of Biomedical Engineering, Biomedical, \\ Imaging Technology Center, Georgia Institute of Technology, Emory University, Atlanta, GA, USA; ${ }^{3}$ Departments of Psychiatry and Surgery, Geisel \\ School of Medicine at Dartmouth, Lebanon, NH, USA; ${ }^{4}$ Department of Electrical Engineering, Pontifícia Universidade Católica do Rio Grande do \\ Sul, Porto Alegre, Rio Grande do Sul, Brazil; ${ }^{5}$ Department of Biostatistics and Bioinformatics, Emory University, Atlanta, GA, USA; ${ }^{6}$ Department of \\ Neurology, Emory University, Atlanta, GA, USA
}

\begin{abstract}
Diffusion tensor imaging (DTI) has been used to evaluate white matter (WM) integrity in major depressive disorder (MDD), with several studies reporting differences between depressed patients and controls. However, these findings are variable and taken from relatively small studies often using suboptimal analytic approaches. The presented DTI study examined WM integrity in large samples of medication-free MDD patients $(n=134)$ and healthy controls $(n=54)$ using voxel-based morphometry (VBM) and tract-based spatial statistics (TBSS) approaches, and rigorous statistical thresholds. Compared with health control subjects, MDD patients show no significant differences in fractional anisotropy, radial diffusivity, mean diffusivity, and axonal diffusivity with either the VBM or the TBSS approach. Our findings suggest that disrupted WM integrity does not have a major role in the neurobiology of MDD in this relatively large study using optimal imaging acquisition and analysis; however, this does not eliminate the possibility that certain patient subgroups show WM disruption associated with depression.

Neuropsychopharmacology (20 I4) 39, I332-1339; doi:I0.1038/npp.2013.345; published online I5 January 2014
\end{abstract}

Keywords: depression; major depressive disorder; diffusion tensor imaging; white matter; fractional anisotropy; magnetic resonance imaging

\section{INTRODUCTION}

Major depressive disorder (MDD) is highly prevalent and a leading cause of worldwide disability (McKenna et al, 2005). Despite decades of research, the neurobiology of MDD remains poorly understood. MDD is increasingly viewed as a disorder of neural circuitry, in which a network of brain regions involved in mood regulation is dysfunctional (Drevets et al, 2008a; Mayberg, 2009). In an effort to better understand the pathophysiology of MDD and develop more effective treatments, much research has focused on delineating the structure and function of this mood regulation network. Although many studies have focused on the function of the network (Drevets et al, 2008b; Hafeman et al, 2012; Mayberg, 2003a, b; Murray et al, 2011; Phillips, 2006), including functional connectivity between

\footnotetext{
*Correspondence: KS Choi, Department of Psychiatry, Emory University or The Wallace $\mathrm{H}$ Coulter, Department of Biomedical Engineering, Biomedical, Imaging Technology Center, Georgia Institute of Technology, Emory University, 101 Woodruff Circle WMB 4306, Atlanta, GA 30345, USA, Tel: +404 727 5528,

E-mail: kisueng.choi@gatech.edu

${ }^{7}$ These authors are co-first authors.

Received I4 August 2013; revised 14 November 2013; accepted 26 November 2013; accepted article preview online 19 December 2013
}

key brain regions (Craddock et al, 2009, 2012; Greicius, 2008, 2007; James et al, 2009; Seminowicz et al, 2004; Sheline et al, 2010), others have focused on the structural connectivity of the network, ie, the white matter (WM) pathways between brain regions (Abe et al, 2010; Blood et al, 2010; Cole et al, 2012; Cullen et al, 2010; Kieseppa et al, 2010; Korgaonkar et al, 2011; Ma et al, 2007; Tha et al, 2013; Wu et al, 2011; Zhu et al, 2011; Zou et al, 2008).

Diffusion tensor imaging (DTI) is a noninvasive, magnetic resonance imaging (MRI) technique used to assess the integrity and fiber orientation of WM. Diffusion measurements reflect the degree of diffusion directionality because diffusion perpendicular to main fiber direction is more hindered by myelin layers and cell membranes than diffusion along the main direction (Le Bihan et al, 2001; Pierpaoli and Basser, 1996). The most commonly used diffusion measurement is fractional anisotropy (FA). In addition to FA, mean diffusivity (MD), radial diffusivity (RD), and axial diffusivity are frequently used for diffusion measurements. MD reflects the total magnitude of diffusion and higher MD has been reported with increased tissue water in edema. RD appears to be modulated by myelin in $\mathrm{WM}$, whereas axial diffusivity is more specific to axonal degeneration (Song et al, 2002). 
Regions of interest (ROIs) and voxel-based analyses have been commonly used to analyze differences in DTI data between groups or within subjects over time. ROI-based analyses have the advantage of being hypothesis directed and less statistically constrained by control for multiple comparisons. However, ROI analyses can be biased because of manual and non-standardized selection of ROIs, and the analyses limited to ROIs cannot identify any differences outside of the chosen ROIs. Voxel-based methods have the advantage of allowing whole-brain analyses and can be fully automated. This eliminates investigator bias (eg, from manual ROI selection).

Two common voxel-based approaches for DTI analyses include voxel-based morphometry (VBM) and track-based spatial statistics (TBSS). VBM of DTI data is a fully automated method that allows investigation of WM integrity in the whole brain, at each voxel (Ashburner and Friston, 2000; Good et al, 2001). TBSS is a newer analytic technique developed to reduce the alignment and smoothing problems that have been reported with VBM (Smith et al, 2006, 2007). Both approaches have been used to assess for differences in WM integrity in a variety of psychiatric disorders including MDD (Bae et al, 2006; Li et al, 2009; Xie et al, 2006).

Numerous DTI studies have looked for WM integrity differences in patients with MDD (Abe et al, 2010; Blood et al, 2010; Cole et al, 2012; Cullen et al, 2010; Kieseppa et al, 2010; Korgaonkar et al, 2011; Ma et al, 2007; Tha et al, 2013; Wu et al, 2011; Zhu et al, 2011; Zou et al, 2008). However, the findings have been highly variable with respect to the location and direction of the difference in FA (Table 1). Six studies report a reduction of FA (in various regions) in MDD patients compared with healthy controls (HCs), whereas another five studies show either an increase or no difference in FA between the groups. The source of this heterogeneity is unclear, but may reflect clinical heterogeneity of different patient cohorts, small samples (and publication bias), and/or the use of suboptimal acquisition/analytic methods. Regarding the last possibility, interpretation and analysis of DTI data may be complicated by a small number of diffusion-weighted directions (more directions yield higher integrity data), anisotropic voxel size, and susceptibility distortion.

In an effort to provide a more definitive analysis of potential WM abnormalities in depressed patients, DTI was performed as part of two large, similarly designed studies on depressed patients and in a group of HCs, all scanned using a common protocol (Dunlop et al, 2012a, b). Using optimized processing methods, VBM and TBSS were performed on these data to assess for differences in FA between the groups. A strict threshold for statistical significance was applied.

\section{MATERIALS AND METHODS}

\section{Participants}

Fifty-four HCs and one hundred and thirty-four MDD patients participated in accordance with Institutional Review Board policies at Emory University. All patients were participants in one of two clinical trials designed to identify treatment-specific imaging biomarkers of treatment outcomes. One trial selected for MDD patients who had never received antidepressant treatment during their lifetime ( $N=98$ : Dunlop et al, 2012a). The other trial enrolled patients who had prior antidepressant treatment but were medication free for at least 2 weeks before the scanning $(N=36$; Dunlop et al, 2012b; McGrath et al, 2013). All participants, including $\mathrm{HC}$, were evaluated for current or past psychiatric disorders using the Structured Clinical Interview for DSM-IV (First et al, 1995) and an interview with a study psychiatrist. HCs were required to have no current or past diagnosis of a mood or psychotic disorder, and no current psychiatric diagnosis other than specific phobia. Current or past medical or neurological disorders were evaluated via medical history, vital signs assessment, physical exam, electrocardiogram, and routine laboratory screening tests, including urine drug screens. Participants with uncontrolled medical conditions (including hypertension or diabetes) or medical or neurological conditions that could interfere with the conduct of the study or interpretation of the study results were excluded, as were those with contraindication to MRI or currently pregnant or breastfeeding women. Eligible depressed patients were adults between 18 and 65 years of age who met criteria for a primary diagnosis of MDD without psychotic features. Patients were excluded if they met lifetime criteria for a lifetime diagnosis of psychotic disorder or bipolar disorder, current obsessive compulsive disorder, substance dependence in the past year, or substance abuse in the past 3 months. Depressed patients were required to have a minimum Hamilton Depression Rating Scale (HDRS) 17item score of $\geqslant 18$ at the screening visit to be eligible for the study. Table 2 shows the demographic information and clinical characteristics of all participants.

\section{Data Acquisition}

Data were acquired on a 3T Tim Trio MRI scanner (Siemens Medical Solutions, Malvern, PA, USA) that permits maximum gradient amplitudes of $40 \mathrm{mT} / \mathrm{m}$. A 12-channel head array coil was used. DTI and $\mathrm{T}_{1}$-weighted data were collected within a single session for each subject and foam cushions were used to minimize head motion. A single-shot spin-echo echo-planar imaging sequence was used with generalized auto-calibrating parallel acquisition with twofold acceleration $(R=2$; Griswold et al, 2002). The parameters used for DTI were: $\mathrm{FOV}=256 \times 256$; $b$ value $=$ $1000 \mathrm{~s} / \mathrm{mm}^{2}$; voxel resolution $=2 \times 2 \times 2 \mathrm{~mm}$; number of slices $=64 ;$ matrix $=128 \times 128 ; \mathrm{TR} / \mathrm{TE}=11300 / 104 \mathrm{~ms} ; 60$ non-collinear directions with four non-diffusion-weighted images $(b=0)$ were acquired twice: once with phase encoding in the anterior to posterior (A-P) direction and once in the posterior to anterior (P-A) direction. To compensate susceptibility distortion, both phase up and down images were acquired. In addition to susceptibility distortion correction, we used slightly longer TR and TE than a typical diffusion protocol because of mechanical vibration of the patient table that caused by the lowfrequency gradient switching associated with the diffusion weighting. High-resolution $\mathrm{T}_{1}$ images were collected using a 3D magnetization-prepared rapid gradient-echo sequence with following parameters: TR/TI/TE $=2600 / 1100 / 3 \mathrm{~ms}$; voxel resolution $=1 \times 1 \times 1 \mathrm{~mm}$; number of slices $=176$; matrix $=224 \times 256$. 
Table I Summary of Diffusion Tensor Imaging Studies in Patients with Major Depressive Disorder using Corrected Whole-Brain Analysis

\begin{tabular}{|c|c|c|c|c|c|c|c|c|c|c|c|c|c|}
\hline \multirow[b]{3}{*}{ Study } & \multicolumn{7}{|c|}{ Participants } & \multicolumn{3}{|c|}{ Imaging parameters } & \multirow[b]{3}{*}{$\begin{array}{l}\text { Data } \\
\text { processing }\end{array}$} & \multirow[b]{3}{*}{$\begin{array}{l}\text { Analysis } \\
\text { method }\end{array}$} & \multirow[t]{2}{*}{ Findings after rigorous threshold } \\
\hline & \multicolumn{3}{|c|}{ Healthy control } & \multicolumn{4}{|c|}{ MDD } & \multirow[b]{2}{*}{$\begin{array}{l}\text { DTI } \\
\text { resolution } \\
(\mathrm{mm})\end{array}$} & \multirow[b]{2}{*}{$\begin{array}{l}\text { Number } \\
\text { of } \\
\text { diffusion } \\
\text { direction }\end{array}$} & \multirow[b]{2}{*}{$\begin{array}{l}\text { Number } \\
\text { of average }\end{array}$} & & & \\
\hline & $n$ & $\begin{array}{l}\text { Age } \\
\text { (mean } \\
\text { (SD)) }\end{array}$ & $\begin{array}{l}\text { Gender } \\
\text { (M/F) }\end{array}$ & $n$ & $\begin{array}{l}\text { Age (mean } \\
\text { (SD)) }\end{array}$ & $\begin{array}{l}\text { Gender } \\
\text { (M/F) }\end{array}$ & $\begin{array}{l}\text { Magnet } \\
\text { strength }\end{array}$ & & & & & & Reduction \\
\hline $\begin{array}{l}\text { Tha et al } \\
\text { (2013) }\end{array}$ & 19 & $36.5(12.5)$ & $13 / 6$ & 19 & $38.6(14.5)$ & $12 / 7$ & $1.5 \mathrm{~T}$ & $\begin{array}{c}1.875 * 1.875 * \\
5\end{array}$ & 12 & 2 & $\begin{array}{l}\text { No distortion } \\
\text { correction } \\
\text { Study-specific template } \\
\text { SPM }\end{array}$ & VBM & $\begin{array}{l}\text { Bilateral frontal WM } \\
\text { Anterior limbs of internal } \\
\text { capsule } \\
\text { Let putamen } \\
\text { Right thalamus } \\
\text { Bilateral cerebellar } \\
\text { hemispheres }\end{array}$ \\
\hline $\begin{array}{l}\text { Cole et al } \\
(2012)\end{array}$ & 66 & $50.4(7.9)$ & $23 / 43$ & 66 & $48.6(8.2)$ & $30 / 36$ & $1.5 \mathrm{~T}$ & $2.5 * 2.5 * 2.5$ & 60 & 1 & $\begin{array}{l}\text { No distortion } \\
\text { correction } \\
\text { JHU DTI template } \\
\text { FSL }\end{array}$ & $\begin{array}{c}\text { TBSS } \\
\text { ROI regions }\end{array}$ & $\begin{array}{l}\text { Splenium } \\
\text { Genu and body of corpus } \\
\text { callosum } \\
\text { Bilateral superior } \\
\text { longitudinal fassiculus } \\
\text { anterior and posterior } \\
\text { corona radiata } \\
\text { Anterior and posterior } \\
\text { limbs of internal capsule }\end{array}$ \\
\hline $\begin{array}{l}\text { Zhu et al } \\
(2011)\end{array}$ & 25 & $\begin{array}{l}20.33 \\
\quad(1.68)\end{array}$ & $10 / 15$ & 25 & $20.55(1.86)$ & $10 / 15$ & $1.5 \mathrm{~T}$ & $2 * 2 * 4$ & 12 & I & $\begin{array}{l}\text { No distortion } \\
\text { correction } \\
\text { MNI template } \\
\text { FSL }\end{array}$ & TBSS & $\begin{array}{l}\text { Left anterior limb of } \\
\text { internal capsule } \\
\text { Right parahippocampa } \\
\text { gyrus } \\
\text { Left posterior cingulate } \\
\text { cortex }\end{array}$ \\
\hline $\begin{array}{l}\text { Wu et al } \\
(2011)\end{array}$ & 21 & $30.4(8.2)$ & $9 / 12$ & 23 & $31.4(8.8)$ & $10 / 13$ & $1.5 \mathrm{~T}$ & $0.94 * 0.94 * 4$ & 12 & 5 & $\begin{array}{l}\text { No distortion } \\
\text { correction } \\
\text { MNI template } \\
\text { DTIStudio and SPM }\end{array}$ & VBM & $\begin{array}{l}\text { Right superior longitudinal } \\
\text { fassiculus } \\
\text { Right middle frontal } \\
\text { Left inferior parietal }\end{array}$ \\
\hline $\begin{array}{l}\text { Korgaon- } \\
\text { kar et al } \\
(2011)\end{array}$ & 39 & $29.6(46.2)$ & $|8 / 2|$ & 29 & $40.5(15.8)$ & $12 / 17$ & $3.0 \mathrm{~T}$ & $\begin{array}{c}1.72 * 1.72 * \\
2.5\end{array}$ & 42 & 1 & $\begin{array}{l}\text { No distortion } \\
\text { correction } \\
\text { MNI template } \\
\text { FSL }\end{array}$ & TBSS & $\begin{array}{l}\text { No difference between } \\
\text { MDD vs controls } \\
\text { Reduction between } \\
\text { meloncholic and controls } \\
\text { in corpus callosum, } \\
\text { dosalateral prefontal, } \\
\text { thalamic projection fiber }\end{array}$ \\
\hline
\end{tabular}


Table I (Continued)

\begin{tabular}{|c|c|c|c|c|c|c|c|c|c|c|c|c|c|c|}
\hline \multirow[b]{3}{*}{ Study } & \multicolumn{7}{|c|}{ Participants } & \multicolumn{3}{|c|}{ Imaging parameters } & \multirow[b]{3}{*}{$\begin{array}{l}\text { Data } \\
\text { processing }\end{array}$} & \multirow[b]{3}{*}{$\begin{array}{l}\text { Analysis } \\
\text { method }\end{array}$} & \multicolumn{2}{|c|}{ Findings after rigorous threshold } \\
\hline & \multicolumn{3}{|c|}{ Healthy control } & \multicolumn{4}{|c|}{ MDD } & \multirow[b]{2}{*}{$\begin{array}{l}\text { DTI } \\
\text { resolution } \\
(\mathrm{mm})\end{array}$} & \multirow[b]{2}{*}{$\begin{array}{l}\text { Number } \\
\text { of } \\
\text { diffusion } \\
\text { direction }\end{array}$} & \multirow[b]{2}{*}{$\begin{array}{l}\text { Number } \\
\text { of average }\end{array}$} & & & \multirow[b]{2}{*}{ Reduction } & \multirow[b]{2}{*}{ Increase } \\
\hline & $n$ & $\begin{array}{l}\text { Age } \\
\text { (mean } \\
(\text { SD)) }\end{array}$ & $\begin{array}{c}\text { Gender } \\
\text { (M/F) }\end{array}$ & $n$ & $\begin{array}{l}\text { Age (mean } \\
\text { (SD)) }\end{array}$ & $\begin{array}{l}\text { Gender } \\
\text { (M/F) }\end{array}$ & $\begin{array}{l}\text { Magnet } \\
\text { strength }\end{array}$ & & & & & & & \\
\hline $\begin{array}{l}\text { Abe et al } \\
(20 \mid 0)\end{array}$ & 42 & $48(13.2)$ & $22 / 20$ & 21 & $48.1(13.5)$ & $11 / 10$ & $1.5 \mathrm{~T}$ & $\begin{array}{c}1.875 * 1.875 * \\
5\end{array}$ & 6 & 4 & $\begin{array}{l}\text { Image-based distorion } \\
\text { correction } \\
\text { Study-specific template } \\
\text { FSL }\end{array}$ & VBM & No difference & \\
\hline $\begin{array}{l}\text { Kieseppa } \\
\text { et al } \\
(20 \mid 0)\end{array}$ & 20 & $42(11.6)$ & $10 / 10$ & 16 & $48.4(10.3)$ & $2 / 14$ & $1.5 T$ & $1.75 * 1.75 * 5$ & 12 & । & $\begin{array}{l}\text { No distortion } \\
\text { correction } \\
\text { MNI template } \\
\text { FSL }\end{array}$ & TBSS & No difference & \\
\hline $\begin{array}{l}\text { Cullen } \\
\text { et al } \\
(2010)\end{array}$ & 14 & $16.81(1.5)$ & $6 / 8$ & 14 & $16.79(1.29)$ & $4 / 10$ & $3.0 T$ & $2 * 2 * 2$ & 30 & । & $\begin{array}{l}\text { Field map distortion } \\
\text { correction } \\
\text { Study-specific template } \\
\text { FSL }\end{array}$ & TBSS & No difference & \\
\hline $\begin{array}{l}\text { Blood } \\
\text { et al } \\
(2010)\end{array}$ & 22 & $35.3(11.6)$ & $10 / 12$ & 22 & $36.3(12.1)$ & $10 / 12$ & $3.0 T$ & $2 * 2 * 2$ & 6 & 6 & $\begin{array}{l}\text { No distortion } \\
\text { correction } \\
\text { MNI template } \\
\text { FSL and Freesurfer }\end{array}$ & $\mathrm{ROI}$ regions & $\begin{array}{l}\text { Dosallateral prefrontal } \\
\text { cortex } \\
\text { Left precentral gyrus }\end{array}$ & $\begin{array}{l}\text { Ventral tefmental } \\
\text { area } \\
\text { Substantia nigra } \\
\text { Right calcarine } \\
\text { cortex }\end{array}$ \\
\hline $\begin{array}{l}\text { Zou et al } \\
\text { (2008) }\end{array}$ & 45 & $31(10.3)$ & $15 / 30$ & 45 & $33.2(8.9)$ & $15 / 30$ & 3.0T & $\begin{array}{c}1.875 * 1.875 * \\
3\end{array}$ & 14 & 2 & $\begin{array}{l}\text { No distortion } \\
\text { correction } \\
\text { MNI template } \\
\text { DTIStudio and SPM }\end{array}$ & VBM & $\begin{array}{l}\text { Left anterior limb of } \\
\text { internal capsule } \\
\text { Left superior longitudinal } \\
\text { fasciculus }\end{array}$ & \\
\hline $\begin{array}{l}\text { Ma et al } \\
\text { (2007) }\end{array}$ & 14 & $27.1(6.7)$ & $2 / 12$ & 14 & $28.9(8)$ & $2 / 12$ & $1.5 T$ & $\begin{array}{c}1.875 * 1.875 * \\
4\end{array}$ & 12 & 5 & $\begin{array}{l}\text { No distortion } \\
\text { correction } \\
\text { MNI template } \\
\text { SPM }\end{array}$ & VBM & $\begin{array}{l}\text { Right middle frontal gyrus } \\
\text { Left lateral } \\
\text { occipitotempolar gyrus } \\
\text { Subgyral WM of the right } \\
\text { parietal lobe } \\
\text { Right angular gyrus }\end{array}$ & \\
\hline
\end{tabular}


Table 2 Demographic and Clinical Characteristics of Participants

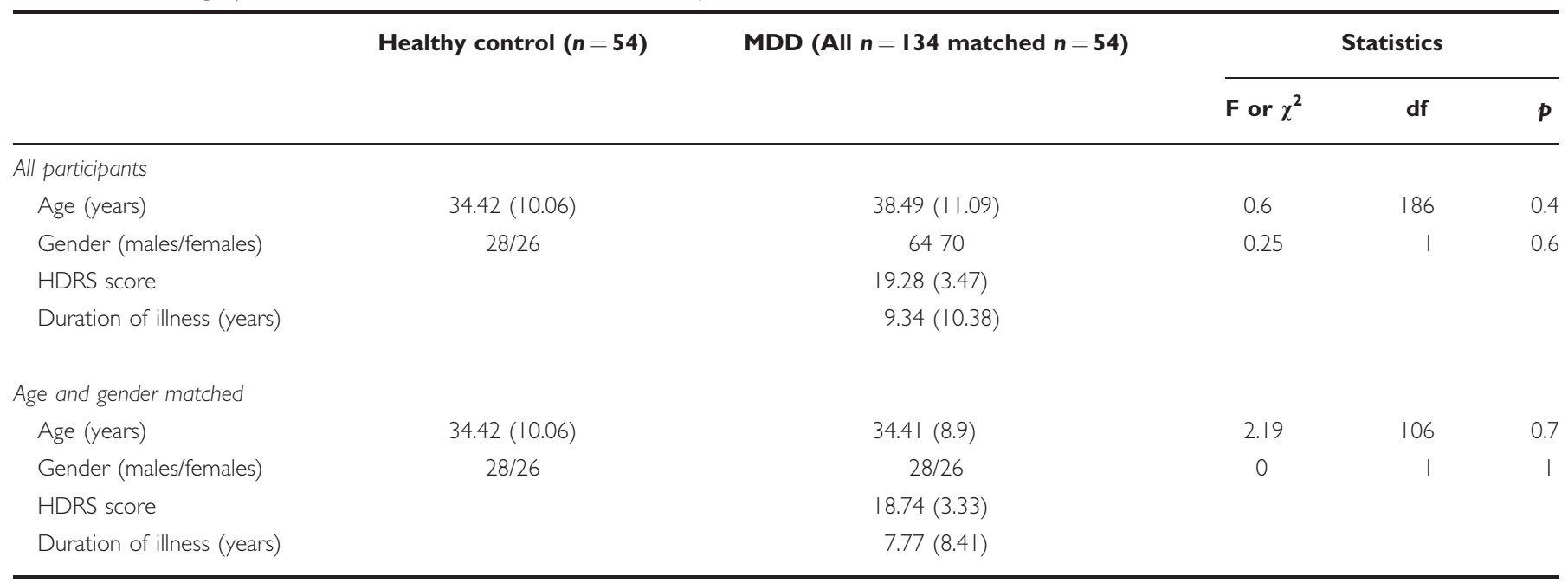

\section{Data Preprocessing}

MRI data were preprocessed using FSL software (http:// www.fmrib.ox.ac.uk/fsl; Analysis Group, FMRIB, Oxford, UK; Smith et al, 2004). Non-brain regions of $T_{1}$ and diffusion-weighted data (both A-P and P-A) were removed using the BET toolbox. To estimate and correct susceptibility-induced distortion of the diffusion-weighted images, a phase reversal distortion correction method (also called Topup correction tool in FSL) was applied on obtained A-P and P-A diffusion data (Andersson et al, 2003). This phase reversal distortion correction method assumes that different phase-encoding diffusion images are caused by an identical magnitude of susceptibility distortion in the phase-encoding direction, and can be resolved by estimating the underlying magnetic field map. By combining the images acquired in opposite phase-encoding directions, the distortion can then be corrected. To help confirm correction, deterministic and probabilistic tractography results of well-known brain WM bundles are inspected for evidence of distortion.

$\mathrm{FA}, \mathrm{RD}, \mathrm{MD}$, and axonal diffusivity maps were generated from phase-reversal distortion-corrected diffusion-weighted data. To improve the signal-to-noise ratio of diffusion tensor fitting, four non-diffusion-weighted images $\left(b_{0}\right)$ are averaged after three of them are aligned to one reference image by affine transformation. Diffusion-weighted image data were aligned to averaged non-diffusion-weighted image by rigid body affine transformation to remove motion and eddy current-induced artifact (Jenkinson et al, 2002). Diffusion tensor, eigenvector, and eigenvalue were then calculated by a tensor fitting model for quantification of directional diffusion and FA (Fdt function within FSL toolbox, Oxford, UK; Behrens et al, 2003).

\section{Study-Specific FA Template}

A study-specific FA template was created using all 188 subjects (MDD and control groups combined). First, each subject's FA image was transformed to a standard FA template (FMRIB58_FA, http://www.fmrib.ox.ac.uk/fsl/data/ FMRIB58_FA.html) using rigid body affine transformation (degree of freedom: 6, FLIRT, FSL) followed by Gaussian smoothing with $3 \mathrm{~mm}$ full-width half-maximum (FWHM) and then averaged across subjects to create the initial studyspecific FA template. A second FA template was created by performing a similar process, but using linear co-registration (degree of freedom: 12) to the first FA template map, followed by blurring with a 3-mm FWHM Gaussian kernel. The final template was created by averaging across subjects. This process was iterated six times using nonlinear image registration (FNIRT, FSL). Results were visually inspected after each iteration for quality control (Supplementary Figure S1). For analyses, each subject's FA map was coregistered to the study-specific template map by performing a linear (FLIRT, dof 12) transformation followed by a nonlinear (FNIRT) transformation. Individual subject FA transformation information to study-specific FA template was saved and used for the other measurement (RD, MD, axonal diffusivity) normalization.

\section{DTI Data Analysis}

For statistical analysis, a permutation-based statistical inference test with threshold-free cluster enhancement (TFCE), using neighborhood voxel information to improve statistical sensitivity. For multiple comparisons, a familywise error (FWE) correction (corrected $p<0.05,10000$ permutations) was used with estimation of cluster size (TFCE-FWE correction and randomize functions within FSL; Bullmore et al, 1999).

\section{VBM}

The normalized FA, RD, MD, and axonal diffusivity map for each subject was smoothed using a 5-mm FWHM Gaussian isotropic kernel to remove possible error caused by anatomical mismatching of like-brain regions.

\section{TBSS}

TBSS was performed using the same FA maps as used for the VBM analyses. For TBSS, the aligned FA maps were 
averaged to create a mean FA map. This mean FA map was then thinned to create a mean FA skeleton representing centers of tracts common to all subjects. FA values less than 0.2 were judged as noise and eliminated to reduce potential confounds introduced by inter-subject variability and partial volume effects (Smith et al, 2006; Smith et al, 2007). The aligned and threshold FA map of each subject was projected onto the mean FA skeleton for the voxel-wise statistical analysis. The same processing steps were applied to $\mathrm{RD}, \mathrm{MD}$, and axonal diffusivity.

\section{Voxel-Wise FA Analysis with MDDs and HCs}

Voxel-wise cross-participant statistics were performed on both VBM and TBSS (skelectonized) analysis using TFCEFWE. Age was used as a covariate and statistical results were adjusted using general linear models. We performed three sets of FA (MD, RD, axonal diffusivity) comparisons: (1) between all $54 \mathrm{HCs}$ and $134 \mathrm{MDD}$ patients; (2) between 98 MDD patients who had never received antidepressant treatment and $36 \mathrm{MDD}$ patients who had previously received antidepressant treatment; and (3) between an age- and gender-matched subset (54 subjects per group) to account for any potential effects because of minor mean age and gender differences among the HCs and MDD patient group (Table 2). In a post-hoc analysis, 20 subjects from each group were randomly selected and compared with both VBM and TBSS analysis; this was iterated 100 times using different subsamples-this post-hoc analysis was performed to assess for the 'false positive' rate in our sample using samples sizes similar to previous analyses.

\section{RESULTS}

Voxel-wise statistics adjusted for age revealed no significant differences in FA, MD, RD, and axonal diffusivity between MDD and HC group for either the VBM or the TBSS analysis. With a gradual decrease in statistical threshold, significant FA differences began appearing in genu of corpus callosum with a $p$-value of 0.15 (TFCE-FWE corrected). In addition to full-group comparisons, the voxel-wise statistical analysis of both the never- and previously treated subsets, and the age- and gender-matched control subset, also found no FA differences for either analysis. Finally, there was no correlation between WM integrity measures and depression severity nor illness duration across the depressed sample.

With the 100 interactive FA analyses using 20 subjects/ group selected randomly for each comparison, statistically significant FA differences were identified for 10 of the TBSS comparisons and 8 of the VBM comparisons $(p<0.05$ TFCE-FWE corrected). The brain regions seen in these 'false positive' results included a spatially diverse set of WM regions. Of note, the genu of the corpus callosum was seen in 8 of the 10 'false positive' TBSS results and 7 of 8 'false' positive VBM results (Supplementary Figure S2).

\section{DISCUSSION}

Despite previous reports of FA abnormalities in depression, this large DTI study found no significant differences in FA (RD, MD, axial diffusivity) between MDD patients and controls using either VBM or TBSS. This included analyses of a subset of age- and gender-matched subjects. In an exploratory analysis, differences in FA between the groups were only seen when the threshold was decreased to a relatively low level-and, even then, the findings appeared 'noisy'. Taken together, these results suggest that disrupted WM integrity does not have a major role in the neurobiology of MDD.

These findings are not entirely inconsistent with prior DTI studies in MDD. When reviewed in toto (Table 1), it is notable that previous studies differ significantly in which brain regions show FA abnormalities. In our post-hoc analysis, where a series of smaller, randomly selected subgroups of patients and controls were compared, about $10 \%$ of comparisons showed 'positive' FA differences despite no differences in the full sample. Similar to the studies in Table 1, the subsample analyses showing FA differences varied considerably in which regions were identified. Interestingly, a region consistently identified as showing FA differences between MDD patients and controls in our post-hoc analysis was the genu of the corpus callosum-a region identified in the previously published reports (Cole et al, 2012; Korgaonkar et al, 2011). Given with the well-known prefrontal distortion in DTI images, it is possible that this region is especially vulnerable to false positive findings in DTI analyses (Wu et al, 2008).

There are several strengths of this study that increase confidence in these findings. First, this is the largest published DTI study to date comparing MDD patients and controls; therefore, these findings likely represent a better estimate, compared with smaller studies, of reliable differences in WM integrity between MDD patients and controls. Second, a study-specific DTI template was created using the full sample $(n=188)$ with an iterative normalization method, so that errors due to co-registration were reduced. Third, a phase reversal distortion correction was applied to the diffusion-weighted images to reduce errors related to well-known frontal distortion in DTI images because of the sinuses (Huang et al, 2008; Wu et al, 2008). Very few of the past published studies have used such a correction that is now relatively standard. Fourth, we utilized the most up-todate analytic methods to reduce possible errors because of diffusion imaging acquisition and statistical comparison. For instance, four non-diffusion $\left(b_{0}\right)$ images were acquired during each scan session, then manually averaged to improve signal to noise ratio. Sixty non-collinear diffusion directions and isotropic voxels were used to improve angular resolution and data integrity (anisotropic voxels in diffusion acquisition can affect tensor modeling and artificially alter FA values (Oouchi et al, 2007)). Finally, well-established diffusion analysis methods were used to calculate FA value, and a rigorous statistical threshold was applied.

Other possibilities exist for why previous reports have identified FA differences in MDD patients $v s$ controls while this study did not. Samples selection differences may be a significant contributing factor, although subjects in this study were carefully evaluated to insure they met diagnostic eligibility criteria using structured diagnostic instruments and rating scales; it is therefore unlikely that they differed significantly from other MDD subjects enrolled in earlier studies. It is possible that subgroups of MDD patients (treatment-resistant, late-onset, early trauma exposure, familial, etc.) may be more likely to have WM abnormalities, although this awaits verification; there were not 
enough patients with these various subtypes of depression in this sample to assess this. Notable in our analysis is that those contrasts showing positive differences could not be attributed to a randomization bias of the study source of either the MDD patients or the control subjects. In general, prior studies used acquisition and analytic methods that were not optimal compared with current standards. This could introduce bias into the analyses increasing the likelihood of a type I error. Finally, we did not have full data on smoking status and history of hypertension for all subjects-therefore, we were not able to assess the effect of these variables on WM integrity between the groups. However, this would only affect our results in a notable way if controls had much higher rates of smoking and/or hypertension, which seems unlikely.

Although this study found no regional differences in FA between MDD patients and controls, this does not argue against the continued use of diffusion imaging to assess WM in the study of MDD. Despite these negative findings in $\mathrm{MDD}$, diffusion imaging remains a powerful tool in the study of neuropsychiatric disorders, particularly in light of oligodendroglia abnormalities in postmortem studies (Harrison, 2002; Ongur and Heckers, 2004; Rajkowska, 2003). As the field progresses, improved acquisition and analytic techniques may allow for the identification of WM abnormalities between groups that are too subtle for current approaches to distinguish. Further, it may be that certain subgroups of depressed patients are more likely to show WM abnormalities, such as patients with extreme treatment resistance or late-onset depression. In addition, it may be that the pathophysiology of depression does not involve the integrity of WM per sé, but rather abnormalities in the WM connections between brain regions involved in mood regulation. To this end, structural connectivity analyses, eg, those using various tractography approaches based on diffusion-weighted data, may be more likely to identify such abnormalities (Hagmann et al, 2008; Sporns et al, 2005).

\section{FUNDING AND DISCLOSURE}

This research was supported by R01 MH073719 (HSM), CIDAR FP105 (HSM), K23 MH077869 (PEH), and a NARSAD Young Investigator Award (PEH). Dr Dunlop is supported by NIMH grant K23 MH086690. Dr Mayberg receives consulting fees from St. Jude Medical Neuromodulation and Eli Lilly and IP licensing fees from St. Jude Medical Neuromodulation. Dr Holtzheimer has received consulting fees from St. Jude Medical Neuromodulation and Cervel Neurotech and an honorarium from Johnson and Johnson. Dr Dunlop has received grant support from Novartis, Pfizer, BMS, Forest, and GSK, and has received consulting fees from Hoffman LaRoche, Pfizer, and BMS. The other authors declare no conflict of interest.

\section{REFERENCES}

Abe O, Takao H, Gonoi W, Sasaki H, Murakami M, Kabasawa H et al (2010). Voxel-based analysis of the diffusion tensor. Neuroradiology 52: 699-710.

Andersson JL, Skare S, Ashburner J (2003). How to correct susceptibility distortions in spin-echo echo-planar images: application to diffusion tensor imaging. NeuroImage 20: 870-888.
Ashburner J, Friston KJ (2000). Voxel-based morphometry-the methods. NeuroImage 11(6 Pt 1): 805-821.

Bae JN, MacFall JR, Krishnan KR, Payne ME, Steffens DC, Taylor WD (2006). Dorsolateral prefrontal cortex and anterior cingulate cortex white matter alterations in late-life depression. Biol Psychiatry 60: 1356-1363.

Behrens TE, Woolrich MW, Jenkinson M, Johansen-Berg H, Nunes RG, Clare S et al (2003). Characterization and propagation of uncertainty in diffusion-weighted MR imaging. Magn Reson Med 50: 1077-1088.

Blood AJ, Iosifescu DV, Makris N, Perlis RH, Kennedy DN, Dougherty DD et al (2010). Microstructural abnormalities in subcortical reward circuitry of subjects with major depressive disorder. PLoS one 5: e13945.

Bullmore ET, Suckling J, Overmeyer S, Rabe-Hesketh S, Taylor E, Brammer MJ (1999). Global, voxel, and cluster tests, by theory and permutation, for a difference between two groups of structural MR images of the brain. IEEE Trans Med Imaging 18: 32-42.

Cole J, Chaddock CA, Farmer AE, Aitchison KJ, Simmons A, McGuffin $P$ et al (2012). White matter abnormalities and illness severity in major depressive disorder. Br J Psychiat 201: 33-39.

Craddock RC, Holtzheimer PE 3rd, Hu XP, Mayberg HS (2009). Disease state prediction from resting state functional connectivity. Magn Resonance Med 62: 1619-1628.

Craddock RC, James GA, Holtzheimer PE III, Hu XP, Mayberg HS (2012). A whole brain fMRI atlas generated via spatially constrained spectral clustering. Hum Brain Mapp 33: 1914-1928.

Cullen KR, Klimes-Dougan B, Muetzel R, Mueller BA, Camchong J, Houri A et al (2010). Altered white matter microstructure in adolescents with major depression: a preliminary study. $\mathrm{J} \mathrm{Am}$ Acad Child Adolesc Psychiatry 49: 173-183 e171.

Drevets WC, Price JL, Furey ML (2008a). Brain structural and functional abnormalities in mood disorders: implications for neurocircuitry models of depression. Brain Struct Funct 213: 93-118.

Drevets WC, Savitz J, Trimble M (2008b). The subgenual anterior cingulate cortex in mood disorders. CNS Spectr 13: 663-681.

Dunlop BW, Binder EB, Cubells JF, Goodman MG, Kelley ME, Kinkead B et al (2012a). Predictors of Remission in Depression to Individual and Combined Treatments (PReDICT): study protocol for a randomized controlled trial. Trials 13: 106.

Dunlop BW, Kelley ME, Mletzko TC, Velasquez CM, Craighead WE, Mayberg HS (2012b). Depression beliefs, treatment preference, and outcomes in a randomized trial for major depressive disorder. J Psychiatr Res 46: 375-381.

First MB SR, Gibbon M, Williams JBW (1995). Structured Clinical Interview for DSM-IV Axis I Disorders-Patient Edition (SCID-I/P, Version 2.0). Biometrics Research Department, New York State Psychiatric Institute: New York.

Good CD, Johnsrude IS, Ashburner J, Henson RN, Friston KJ, Frackowiak RS (2001). A voxel-based morphometric study of ageing in 465 normal adult human brains. NeuroImage 14(1 Pt 1): 21-36.

Greicius M (2008). Resting-state functional connectivity in neuropsychiatric disorders. Curr Opin Neurol 21: 424-430.

Greicius MD, Flores BH, Menon V, Glover GH, Solvason HB, Kenna $\mathrm{H}$ et al (2007). Resting-state functional connectivity in major depression: abnormally increased contributions from subgenual cingulate cortex and thalamus. Biol Psychiatry 62: 429-437.

Griswold MA, Jakob PM, Heidemann RM, Nittka M, Jellus V, Wang J et al (2002). Generalized autocalibrating partially parallel acquisitions (GRAPPA). MagnReson Med 47: 1202-1210.

Hafeman DM, Chang KD, Garrett AS, Sanders EM, Phillips ML (2012). Effects of medication on neuroimaging findings in bipolar disorder: an updated review. Bipolar Disord 14: 375-410.

Hagmann P, Cammoun L, Gigandet X, Meuli R, Honey CJ, Wedeen VJ et al (2008). Mapping the structural core of human cerebral cortex. PLoS Biol 6: e159.

Harrison PJ (2002). The neuropathology of primary mood disorder. Brain 125(Pt 7): 1428-1449. 
Huang H, Ceritoglu C, Li X, Qiu A, Miller MI, van Zijl PC et al (2008). Correction of B0 susceptibility induced distortion in diffusion-weighted images using large-deformation diffeomorphic metric mapping. Mag Reson Imaging 26: 1294-1302.

James GA, Kelley ME, Craddock RC, Holtzheimer PE, Dunlop BW, Nemeroff CB et al (2009). Exploratory structural equation modeling of resting-state fMRI: applicability of group models to individual subjects. NeuroImage 45: 778-787.

Jenkinson M, Bannister P, Brady M, Smith S (2002). Improved optimization for the robust and accurate linear registration and motion correction of brain images. Neurolmage 17: 825-841.

Kieseppa T, Eerola M, Mantyla R, Neuvonen T, Poutanen VP, Luoma $\mathrm{K}$ et al (2010). Major depressive disorder and white matter abnormalities: a diffusion tensor imaging study with tract-based spatial statistics. J Affect Disord 120: 240-244.

Korgaonkar MS, Grieve SM, Koslow SH, Gabrieli JD, Gordon E, Williams LM (2011). Loss of white matter integrity in major depressive disorder: evidence using tract-based spatial statistical analysis of diffusion tensor imaging. Hum Brain Mapp 32: 2161-2171.

Le Bihan D, Mangin JF, Poupon C, Clark CA, Pappata S, Molko N et al (2001). Diffusion tensor imaging: concepts and applications. J Magn ResonImaging 13: 534-546.

Li L, Coles CD, Lynch ME, Hu X (2009). Voxelwise and skeletonbased region of interest analysis of fetal alcohol syndrome and fetal alcohol spectrum disorders in young adults. Hum Brain Mapp 30: 3265-3274.

Ma N, Li L, Shu N, Liu J, Gong G, He Z et al (2007). White matter abnormalities in first-episode, treatment-naive young adults with major depressive disorder. Am J Psychiatry 164: 823-826.

Mayberg HS (2003a). Modulating dysfunctional limbic-cortical circuits in depression: towards development of brain-based algorithms for diagnosis and optimised treatment. Br Med Bull 65: 193-207.

Mayberg HS (2003b). Positron emission tomography imaging in depression: a neural systems perspective. Neuroimaging ClinN Am 13: 805-815.

Mayberg HS (2009). Targeted electrode-based modulation of neural circuits for depression. J Clin Invest 119: 717-725.

McGrath CL, Kelley ME, Holtzheimer PE, Dunlop BW, Craighead WE, Franco AR et al (2013). Toward a neuroimaging treatment selection biomarker for major depressive disorder. JAMA Psychiatry 70: 821-829.

McKenna MT, Michaud CM, Murray CJ, Marks JS (2005). Assessing the burden of disease in the United States using disability-adjusted life years. Am J Preventive Med 28: 415-423.

Murray EA, Wise SP, Drevets WC (2011). Localization of dysfunction in major depressive disorder: prefrontal cortex and amygdala. Biol Psychiatry 69: e43-e54.

Ongur D, Heckers S (2004). A role for glia in the action of electroconvulsive therapy. Harvard Rev Psychiatry 12: 253-262.

Oouchi H, Yamada K, Sakai K, Kizu O, Kubota T, Ito H et al (2007). Diffusion anisotropy measurement of brain white matter is affected by voxel size: underestimation occurs in areas with crossing fibers. AJNR Am J Neuroradiol 28: 1102-1106.
Phillips ML (2006). The neural basis of mood dysregulation in bipolar disorder. Cogn Neuropsychiatry 11: 233-249.

Pierpaoli C, Basser PJ (1996). Toward a quantitative assessment of diffusion anisotropy. Magn Reson Med 36: 893-906.

Rajkowska G (2003). Depression: what we can learn from postmortem studies. Neuroscientist 9: 273-284.

Seminowicz DA, Mayberg HS, McIntosh AR, Goldapple K, Kennedy S, Segal Z et al (2004). Limbic-frontal circuitry in major depression: a path modeling metanalysis. NeuroImage 22: 409-418.

Sheline YI, Price JL, Yan Z, Mintun MA (2010). Resting-state functional MRI in depression unmasks increased connectivity between networks via the dorsal nexus. Proc Natl Acad Sci USA 107: 11020-11025.

Smith SM, Jenkinson M, Johansen-Berg H, Rueckert D, Nichols TE, Mackay CE et al (2006). Tract-based spatial statistics: voxelwise analysis of multi-subject diffusion data. NeuroImage 31: 1487-1505.

Smith SM, Jenkinson M, Woolrich MW, Beckmann CF, Behrens TE, Johansen-Berg $\mathrm{H}$ et al (2004). Advances in functional and structural MR image analysis and implementation as FSL. NeuroImage 23(Suppl 1): S208-S219.

Smith SM, Johansen-Berg H, Jenkinson M, Rueckert D, Nichols TE, Miller KL et al (2007). Acquisition and voxelwise analysis of multi-subject diffusion data with tract-based spatial statistics. Nature protocols 2: 499-503.

Song SK, Sun SW, Ramsbottom MJ, Chang C, Russell J, Cross AH (2002). Dysmyelination revealed through MRI as increased radial (but unchanged axial) diffusion of water. NeuroImage 17: 1429-1436.

Sporns O, Tononi G, Kotter R (2005). The human connectome: A structural description of the human brain. PLoS Comp Biol 1: e42.

Tha KK, Terae S, Nakagawa S, Inoue T, Kitagawa N, Kako Y et al (2013). Impaired integrity of the brain parenchyma in nongeriatric patients with major depressive disorder revealed by diffusion tensor imaging. Psychiatry Res 212: 208-215.

Wu F, Tang Y, Xu K, Kong L, Sun W, Wang F et al (2011). Whiter matter abnormalities in medication-naive subjects with a single short-duration episode of major depressive disorder. Psychiatry Res 191: 80-83.

Wu M, Chang LC, Walker L, Lemaitre H, Barnett AS, Marenco S et al (2008). Comparison of EPI distortion correction methods in diffusion tensor MRI using a novel framework. Medical Image Computing and Computer-Assisted Intervention. MICCAI. 11th International Conference on Medical Image Computing and Computer-Assisted Intervention. Springer: MICCAI 2008, Part II, LNCS 5242, (Pt 2), pp 321-329.

Xie S, Xiao JX, Gong GL, Zang YF, Wang YH, Wu HK et al (2006). Voxel-based detection of white matter abnormalities in mild Alzheimer disease. Neurology 66: 1845-1849.

Zhu X, Wang X, Xiao J, Zhong M, Liao J, Yao S (2011). Altered white matter integrity in first-episode, treatment-naive young adults with major depressive disorder: a tract-based spatial statistics study. Brain Res 1369: 223-229.

Zou K, Huang X, Li T, Gong Q, Li Z, Ou-yang L et al (2008). Alterations of white matter integrity in adults with major depressive disorder: a magnetic resonance imaging study. J Psychiatry Neurosci 33: 525-530.

Supplementary Information accompanies the paper on the Neuropsychopharmacology website (http://www.nature.com/npp) 